\title{
LA TRADUCCIÓN DE JOB 2,10A
}

"Si aceptamos de Dios los bienes, ¿no vamos a aceptar los males?" Esta es la traducción más frecuente de Job 2,10a: ${ }^{1}$ gam 'et-hațôb $n^{e} q a b$ -

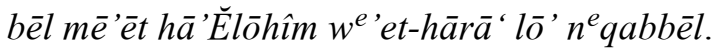

No habiendo justificación para la condicional y, menos aún, para la interrogación, otros traducen: "Yes, the good we accept from Elohim, then we must certainly also accept the evil". ${ }^{2}$ Así, para no perder el sentido tradicional, se atropella el texto. En efecto, ¿de dónde saldría "then we must certainly"?

La discusión sobre este particular es de gran importancia, no solamente para la traducción del libro de Job, sino también para la teología bíblica. Que Dios dé el mal y el hombre lo reciba sin cuestionamientos, no concuerda con Gn 1,31: "vio Dios todo lo que había hecho y todo era muy bueno".

Que Dios esté por encima del bien y del mal (cf. Is 45,7: "Yo modelo la luz y creo la tiniebla; yo hago la dicha y creo la desgracia. Yo soy Yahvé, el que hago todo esto". Cf. tb. Dt 32,39); que pruebe con el mal al hombre y éste deba superar la prueba (Dt 8,2), asumiendo el mal por un bien superior, es otra cosa. Este es el caso de Job. Pero no la quietud sin cuestionamientos que aparece en la traducción errónea de 2,10a.

${ }^{1}$ Cf. Biblia Traducción Interconfesional (BTI), 2008 '.

${ }^{2}$ Cf. W.L. MicheL, Job in the Light of Northwest Semitic, Roma - 1987, 28.33-34. 
Efectivamente, la traducción del texto hebreo, conforme a su original, no debe tener el inicio condicional ni la interrogación final, y suena: “El bien recibimos de Dios, no el mal!"

\section{Problema para el contexto}

El libro de Job gira en torno al "mal que el Señor había traído sobre él" (42,11; cf. 2,11), sin motivo. Job es probado como Abrahán (Gn 22) y tiene que demostrar su fe. Abrahán, hombre de fe, supera la dificultad mostrándose dispuesto a sacrificar a su único hijo, basado en que "Dios proveerá el cordero para el holocausto" (Gn 22,8). Job, un extranjero piadoso, se ve en la dificultad de formalizar su fe en los esquemas de Yahvé, el Dios de la elección y de la alianza; y demostrará esa fe con la protesta, premiada con la respuesta de Dios. ${ }^{3}$ En efecto, la segunda prueba de Yahvé a Job crea una expectativa que solamente se resuelve con la intervención de Yahvé y la retractación de Job. De modo que, en el contexto general del libro, la traducción con interrogativa negativa precedida de condicional es una anticipación del desenlace final, previsto para el momento de la respuesta final de Job (40,4-5 y 42,1-6). Vamos un poco más al detalle.

En el espíritu de la primera prueba (cap. 1), Job no tuvo problemas con Dios $(1,22)$, nunca recibió ningún mal porque nunca lo mereció, y las palabras del tentador (Satán) dan testimonio de ello $(1,10)$ : “¿No hiciste acaso una defensa alrededor de él, de su casa y de todo lo que él posee? Bendijiste el trabajo de sus manos, y sus posesiones aumentan en la región”. Más aún, Job nunca recibió males sin motivo. El mal que sufrió en la primera prueba, por causa de sus hijos, debió asumirlo por ser su padre, y esa fue la prueba del justo en la antigua novela (cf. 1 Cro 7,22).

Recibir males sin motivo es la novedad de la segunda prueba $(2,3$ : "destruirlo sin motivo"). De aquí en adelante, los sentimientos de Job van

3 Pienso que la relación existente entre Dios y Job es una relación de alianza, aunque en términos disimulados. En efecto, Job es beneficiado por Dios y es su siervo $(1,8 ; 2,3)$; Yahvé es el Dios de Job, de quien depende en todo y de quien exige respuesta; entre los dos hay un acuerdo de base por lo que Dios puede probar a Job y éste puede reclamar a Dios; Dios, en su poder soberano, responde a su siervo que reclama su derecho. Beneficios de Dios - Mandamientos para el siervo - Bendiciones o Maldiciones condicionadas al cumplimiento o no, con un sentido claro de la retribución de la alianza tejiendo toda la trama, es lo que encontramos en el libro de Job. 
cambiando radical, pero paulatinamente. El primer síntoma del cambio de Job es apartarse y sentarse sobre la ceniza $(2,8)$. Por lo de "necia" -en la respuesta de Job a su mujer $(2,10)$-, entendemos el enfado de Job, aunque defienda el hecho de haber siempre recibido bienes. Sin pecar con los labios, su corazón ya estaba colmado y, desde "la ceniza", Job maldice su día ( 3,1 . Nótese que 3,1 es todavía parte del prólogo).

A partir de 3,2, Job exterioriza, cada vez con más convicción, lo que lleva en el corazón. Comienza con los “¿por qué?” $(3,11.20-23)$ y prepara su defensa $(13,18)$. Ya en la protesta, habla expresamente de que "esperaba bienes" y le "vinieron males" $(30,26)$. Ahora, sólo espera que YHWH se defienda (31,35: "que me responda").

Con la respuesta de YHWH $(38,1 ; 42,6)$, Job finalmente consigue tranquilizarse $(40,4-5 ; 42,1-6)$.

De modo que aquella traducción, condicional - interrogativa negativa, además crear un problema teológico innecesario, entorpece el fluir de la narrativa y anticipa inoportunamente el verdadero desenlace de la intriga que es, precisamente, la retractación de Job y la confirmación de Dios en 42,7-10.

Esta traducción "tradicional" da pie para decir que, en todo el prólogo (considerando como prólogo los capítulos 1 y 2), Job aparece con una actitud paciente, mientras que sólo en los poemas, a partir de 3,2, comenzaría a ser impaciente. Esta interpretación no tiene en cuenta los pequeños detalles que indican los cambios en la actitud de Job, en perfecta armonía con todo el resto. Más allá de la infidelidad al texto, la traducción de Job 2,10a, con frase interrogativa negativa precedida por una condicional, destruye el contexto y toda la obra pierde la dinámica propia de una narrativa que se respete.

\section{Maltrato del texto}

Dos son los problemas gramaticales a dilucidar: cómo entender la partícula inicial gam y cómo suponer implícita la partícula interrogativa, $h \breve{a}$, junto al adverbio $l \bar{o}$ '. 
Alonso-Sicre traducen: "Si aceptamos de Dios los bienes, ¿no vamos a aceptar los males?", ${ }^{4}$ sin que se pueda saber de dónde aparece la condicional y sin dar explicación ninguna sobre la interrogación.

Fohrer no se sirve de la autoridad de GKC $\$ 150$ a para decir que Job 2,10a no necesita de la partícula interrogativa, para llegar a ser una pregunta, ${ }^{5}$ como lo hace en 2,9, para la pregunta de la mujer de Job. En 2,10a, Fohrer simplemente cambia $l \bar{o}$ ' en hălō': “...und das Böse sollten wir nicht annehmen?", explicando que es una necesidad del contexto. ${ }^{6}$ El énfasis sobre las palabras, ${ }^{7}$ en este caso, no parece razón suficiente para suponer la presencia de una interrogación. Sería conveniente que también el texto de Job 2,10a -entre los textos citados por GKC §150a- fuera reexaminado, como lo fueron otros textos, ${ }^{8}$ para no ser considerado interrogativo de aquí en adelante. Efectivamente, no puede ser que, sólo en el texto de Job 2,10a, la partícula $l \bar{o}$ ' tenga el mismo valor de $h a ̆ l \bar{o}$ '.

Horst toma la $w$ de $w^{e}$ 'et-hāra $\bar{a}^{\prime}$ como una partícula adversativainterrogativa: “...das Böse aber sollen wir nicht hinnehmen?", hay justificación para la interrogación.

La traducción de Maag quiere resolver el problema de gam: "Wie eine Törin redet, so willst auch du reden", lo cual Berges explica como un uso esporádico de gam en el final de la frase. ${ }^{10}$ Pero esta solución complica más el problema, dejando sin soporte la traducción interrogativa de la frase siguiente.

${ }^{4}$ L. Alonso SChÖKEL - J. L. SICRE Díaz, Job. Comentario teológico y literario, NBE, Madrid - 1983, 106; La Biblia de nuestro pueblo, Bilbao - 2007². Esta es la traducción más común.

${ }^{5}$ G. FoHRER, Das Buch Hiob, Gütersloh - 19892, 99: "Die Frage braucht nicht durch ein besonderes Fragewort eingeführt zu werden".

${ }^{6}$ FOHRER, Hiob, 100: "... wenn schon der Zusammenhang die Frage ausdrückt".

7 Cf. W. Gesenius - E. Kautzsch, Hebrew Grammar (ed. A.E. Cowley), Oxford 1946, impresión de 1990) §150a: "Frequently the natural emphasis upon the words is of itself sufficient to indicate an interrogative sentence as such".

${ }^{8}$ H.G. MitCheL, "The Omission of the Interrogative Particle", Old Testament and Semitic Studies, Chicago - 1907, i,113ss, citados por el mismo GKC §150, rescató algunos textos que, como éste de Job 2,10, fueron considerados interrogativos porque, supuestamente, el contexto lo exigía.

${ }^{9}$ F.HORST, Hiob, Neukirchen-Vluyn - 1969, 21.

${ }^{10}$ U. BERGES, "Der ljobrahmen (Ijob 1,1-2,10; 42,7-17). Theologische Versuche angesichts unschuldigen Leidens", BZ.NF 39 (1995) 239; cf. V. MAAG, Hiob: Wandlung und Verarbeitung des Problems in Novelle, Dialogdichtung und Spätfassungen, Göttingen - 1982, 91, n. 11. 
Michel toma gam y $l \bar{o}$ ' como enfáticas, consiguiendo así cambiar el sentido original, sin tener que usar la condicional y la interrogativa: "Yes, the good we accept from Elohim, then we must certainly also accept the evil". ${ }^{11}$ Bien por lo de las enfáticas, pero, ¿de dónde aparece aquel "then we must"? Michel sigue a Noestscher, quien toma gam como adverbio (de $g+m)$ referido a $t^{e} d a b b \bar{e} r$, "hablas en voz alta", y toma $l \bar{o}$ ', como enfática. ${ }^{12}$ El adverbio "certainly" correspondería a la partícula enfática $l \bar{o}$ ', pero la frase "then we must" continúa sin explicación.

Brongers, con relación a $l \bar{o}$ 'y hălō', toma en cuenta $\mathrm{Lm} 3,38$, pero no Job 2,10 , tal vez porque no lo consideraba un caso igual. ${ }^{13}$ Efectivamente, no es igual porque, en Lamentaciones, ya precede una pregunta. ${ }^{14}$

En cuanto a los problemas textuales, dos Mss omiten gam.

Los LXX traducen gam: con ei. ¿Quizá porque lean 'im en lugar de gam, obedeciendo a algún texto hebreo diverso, o porque ya comenzaron a interpretar el texto hebreo? Pero ei, introduciendo la condicional, no siempre precede a una interrogación (cf. Is 49,15).

La Vulgata ya lleva la frase condicional y la interrogativa: "si bona suscepimus de manu Domini quare mala non suscipiamus". ${ }^{15}$

La edición revisada y aumentada de 1998 de la Biblia de Jerusalén ya modifica el sentido de la frase, aunque tenga que hacer una paráfrasis: "¡Resulta que estamos dispuestos a recibir de Dios lo bueno y no lo estamos para recibir lo malo!"

\section{Propuesta}

Para la traducción del versículo que nos ocupa, propongo tomar gam como una simple conjunción aditiva, "et, atque" (cf. Is 13,3; 47,3; Sal 118,11), ${ }^{16}$ o como partícula enfática, ${ }^{17}$ y dejar inalterado el valor de

${ }^{11}$ MICHEL, JOb, 28.33-34.

${ }^{12}$ Cf. F. NoetsCher, "Zum emphatischen Lamed", VT 3 (1953) 375.

${ }^{13}$ Cf. H. A. Brongers, "Some Remarks on the Biblical Particle $h l^{\prime \prime \prime}$, OTS 21 (1981) 177-189. 232.

${ }^{14}$ Cf. G.S. Glanzman, "Two Notes: Am 3,15 and Os 11,8-9", CBQ 23 (1961) 231-

15 Biblia Sacra iuxta Vulgatam Versionem (ed. B. Fischer), Stuttgart - 1975/2.

${ }^{16}$ Cf. F. ZORELL, Lexicon hebraicum Veteris Testamenti, Roma - 1940/1967, 154. 
lō', sin sustituirlo por hălō'. De ahí la traducción: “(sí), de Dios recibimos el bien, y no recibimos el mal!”; o “ ¡El bien recibimos de Dios, no el mal!"

Encontramos apoyo para esta traducción en los sintagmas parecidos:

gam 'et-hațtôb n'qabbēl mē'èt ha'Elōhîm

we'et-hārā' lón' n'qabbēl

(gam) 'et + objeto + verbo

$w^{\text {e'et }}+$ objeto $+\bar{o}^{\prime}+$ verbo

¡(Si), de Dios recibimos el bien, y no recibimos el mal!

En relación con $l \bar{o}$ ' sin interrogación, en Gn $15,10^{18}$ leemos:

way ${ }^{\mathrm{e}}$ battēr 'ōtām battāwek...

w'et-hașippōr lō' bātār

verbo + 'et + objeto

$w^{e}$ et + objeto $+\bar{o}^{\prime}+$ verbo

[Abrahán] los partió por el medio... ; y a las aves no las partió.

En relación con la partícula enfática gam, en $2 \operatorname{Re} 23,27^{19}$ leemos:

gam 'et-Yehûdāh 'āsîr mēal pānay

ka’ăšer hăsirōtî 'et-Yiśrāāèl

gam 'et- + objeto + verbo

verbo + 'et- + objeto

Sí, a Judá repeleré de mi presencia, como repelí a Israel.

17 Cf. L. KöHLER - W. Baumgartner, Lexicon in Veteris Testamenti Libros, Leiden 1958, 186; F. Brown - S. R. Driver - C. A. BriggS, "גם" II, A Hebrew and English Lexicon of the Old Testament, Oxford - 1952, 169 a; R. GoRDIS, The Book of Job, New York - 1978, 22; S. R. DRIVER - G. B. GRAY, The Book of Job, Edinburgh - 1977, 25-26; II,14. J. E. SMith, "גמם (gmm)" Dicionário Internacional de Teologia do Antigo Testamento (ed. R. L. Harris), São Paulo - 1998, 275-276: "Às vezes, em traduções em português, gam é totalmente ignorado".

${ }^{18} \mathrm{Cf}$. otros casos en Gn 2,16-17; 4,4-5; 9,23; Nm 18,31; Jos 9,14; $10,28 \ldots$

${ }^{19} \mathrm{Cf}$. otros casos en 2 Re 23,15; Job 12,3a; Is 49,25; Jr 33,21; Ez 18,10-11. 
En relación con la partícula enfática gam y el $l \bar{o}^{\prime}$ sin interrogación (con cambio de sujeto), en Is $49,15 b^{20}$ leemos:

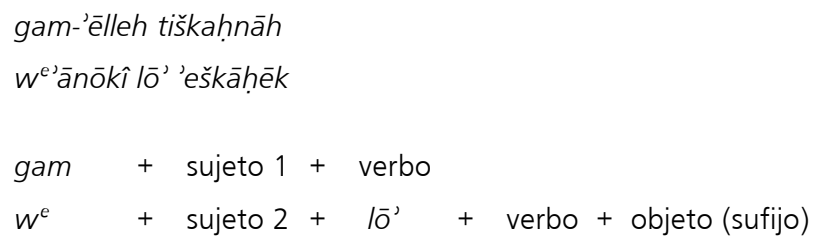

También si ellas se olvidaran, yo no me olvidaré de ti.

Los LXX traducen la primera frase con ei, pero no por eso la frase siguiente es traducida con interrogativa.

Mi propuesta no es totalmente nueva. Jacob ya propone una alternativa: "das Gute sollen wir von Gott annehmen?" o: "das Gute nehmen wir von Gott an..."

Pero, sobre todo, Vogels ya traduce más conforme al texto masorético, argumentando precisamente la autoridad del texto: "We indeed receive good from God's hand and do not receive evil". ${ }^{22}$ Finalmente, Peake traduce: "Good shall we receive at the hand of God, and evil shall we not receive", ${ }^{23}$ en consonancia con el pasado de Job que fue siempre bendecido.

\section{Conclusión}

No hay alternativa, también en Job 2,10a del texto masorético se debe leer simplemente una negación, sin la condicional de la frase que la precede: “ $¡ E l$ bien recibimos de Dios, no el mal!”

${ }^{20}$ Cf. otros casos en Gn 9,3-4; 20,3-4; 28, 16; 38,14; 42,3-4...

${ }^{21}$ B. JACOB, "Erklärung einer Hiobstellen", ZAW 32 (1912) 281-282.

${ }^{22}$ W. Vogels, "Job's Empty Pious Slogans (Job 1,20-22; 2,8-10)", The Book of Job (ed. W. A. M. Beuken), Leuven - 1994, 373: "Since Job's answer is not introduced by an interrogation mark, it can be read as a declarative statement."

${ }^{23}$ A. S. PEAKE, "Job: The Problem of the Book", Theodicy in the Old Testament (ed. J.L. Crenshaw), IRT 4, Philadelphia - 1983, 100: "'Good shall we receive at the hand of God, and evil shall we not receive'... continuance of the old relation". 
Esta traducción respeta el texto, hace que el contexto recupere la seriedad que la narrativa exige y evita un problema teológico inexistente, atribuyendo a Dios el origen del mal.

Con esta traducción, la defensa que Job hace de Dios delante de la mujer es más natural y auténtica que con aquellas que hemos cuestionado. Este tipo de traducciones, que no convencen a la crítica de los lectores atentos, ${ }^{24}$ supone que Job, en su vida, ya enfrentó y superó la dificultad de aceptar un mal sin motivo. Lo cual es contrario al texto del libro de Job. Esa experiencia es nueva en la vida de Job y su lucha por defender la fe y confianza en su Dios va apenas a comenzar. Antes de esta provocación con la desgracia sin motivo de la segunda prueba, Job recibió sólo bienes porque siempre los mereció.

La necedad de la mujer -tentación de Job- consiste en el olvido de todo el bien que recibió Job en su pasado (cf. Jue 8,34; Sal 106,13). Decir que Job está dispuesto a aceptar, ahora, la desgracia sin motivo es una contradicción con el espíritu del prólogo y hace inútil la presencia de todos los poemas. Es precisamente en los poemas donde Job prepara y formula su protesta, provocando, a su vez, la respuesta de Dios y produciéndose el desenlace.

GALO SÁNCHEZ BRAVO

CÚCUTA - COLOMBIA sanchezgalo@hotmail.com

24 Cf. W. Vogels, "Job's Superficial Faith in His First Reactions to Suffering (Job 1:20-23; 2:8-10)", EeT 25 (1994) 373; cf. E.M. Good, In Turns of Tempest: A Reading of Job with a Translation, Stanford - 1990, 52. 